\title{
Photosynthesis and lipid composition of the Antarctic endemic rhodophyte Palmaria decipiens: effects of changing light and temperature levels
}

\author{
Susanne Becker · Martin Graeve · Kai Bischof
}

Received: 16 November 2009 / Revised: 23 December 2009 / Accepted: 25 January 2010 / Published online: 9 March 2010

(C) Springer-Verlag 2010

\begin{abstract}
In coastal waters, Antarctic rhodophytes are exposed to harsh environmental conditions throughout the year, like low water temperatures ranging from $-1.8^{\circ} \mathrm{C}$ to $2{ }^{\circ} \mathrm{C}$ and high light during the summer season. Photosynthetic performance under these conditions may be affected by slowed down enzymatic reactions and the increased generation of reactive oxygen species. The consequence might be a chronic photoinhibition of photosynthetic primary reactions related to increased fragmentation of the D1 reaction centre protein in photosystem II. It is hypothesized that changes in lipid composition of biomembranes may represent an adaptive trait to maintain D1 turnover in response to temperature variation. The interactive effects of high light and low temperature were studied on an endemic Antarctic red alga, Palmaria decipiens, sampled from two shore levels, intertidal and subtidal, and exposed to mesocosm experiments using two levels of natural solar radiation and two different temperature regimes $\left(2-5^{\circ} \mathrm{C}\right.$ and $\left.5-10^{\circ} \mathrm{C}\right)$. During the experimental period of 23 days, maximum quantum yield of photosynthesis decreased in all treatments, with the intertidal specimens exposed at $5-10^{\circ} \mathrm{C}$ being most affected. On the pigment level, a decreasing ratio of phycobiliproteins to chlorophyll a was found in all treatments. A pronounced decrease in D1 protein concentration occurred in subtidal specimens exposed at $2-5^{\circ} \mathrm{C}$. Marked changes in lipid composition, i.e. the ratio of saturated to unsaturated fatty acids, indicated an effective
\end{abstract}

S. Becker $(\varangle) \cdot$ K. Bischof

Department of Marine Botany, University of Bremen,

Leobener Strasse NW2, 28359 Bremen, Germany

e-mail: sbecker@ipoe.uni-kiel.de

M. Graeve

Biosciences-Ecological Chemistry, Alfred Wegener Institute, Am Handelshafen 12, 27570 Bremerhaven, Germany response of specimens to temperature change. Results provide new insights into mechanisms of stress adaptation in this key species of shallow Antarctic benthic communities.

Keywords Antarctica $\cdot$ Palmaria decipiens $\cdot$ Lipid composition $\cdot$ Photosynthesis

$\begin{array}{ll}\text { Abbreviations } & \\ \text { ANOVA } & \text { Analysis of variance } \\ \text { FA } & \text { Fatty acid } \\ \text { ETRmax } & \text { Maximal electron transport rate } \\ \text { FV/Fm } & \text { Maximum quantum yield } \\ \text { PAR } & \text { Photosynthetically active radiation } \\ \text { PS II } & \text { Photosystem II } \\ \text { PI-curve } & \text { Photosynthesis-irradiance curve } \\ \text { PUFA } & \text { Poly-unsaturated fatty acid } \\ \text { UV radiation } & \text { Ultraviolet radiation }\end{array}$

\section{Introduction}

Antarctic coastal ecosystems are characterized by low temperatures throughout the year (Wiencke and tom Dieck 1989), and intertidal organisms may be exposed to extreme subzero temperatures during low tides. This temperature regime has evolved by large-scale atmospheric and hydrographic conditions within the Antarctic convergence (Wiencke and tom Dieck 1989 and references therein). Organisms inhabiting the intertidal and shallow subtidal zones of Antarctic shores have to be strongly adapted to this regime, which is additionally characterized by a high seasonality of light availability. In particular, sessile organisms may strongly rely on effective physiological adaptation mechanisms related to this specific abiotic environment. 
In general, low temperatures slow down enzymatic reactions and synthetic pathways and result in a decrease in membrane fluidity (Gurr et al. 2002; Peterson et al. 2007). To photosynthesizing organisms, as e.g. benthic macroalgae in Polar regions, the combination of low temperature and high radiation conditions is particularly challenging: because of reduced electron drainage as a result of the slowed down activity of Calvin cycle enzymes, the generation of reactive oxygen species may increase. Under these circumstances, the degradation of the D1 reaction centre protein of photosystem II is promoted (Aro et al. 1993, 2005; Bischof et al. 1999). D1 protein is characterized by a rapid and permanent turnover, which might become unbalanced under high radiation stress. A limiting factor in the reintegration of de novo-synthesized protein into the PS II reaction centres is the velocity of lateral diffusion through the thylakoid membrane (Aro et al. 2005). In this process, membrane fluidity represents the determinant factor, which is highly controlled by temperature. In particular, low temperatures induce a number of alterations in cellular components, including the extent of fatty acid unsaturation, the composition of glycerolipids, the positional redistribution of saturated and unsaturated fatty acids within lipid molecules, changes in the lipid/protein ratio, and activation of ion channels (Guschina and Harwood 2006 and reference therein). At a given temperature, membrane fluidity is determined by the respective degree of unsaturation of fatty acids.

It is generally accepted that in organisms from cold environments, membranes exhibit a higher amount of unsaturated fatty acids to maintain membrane fluidity (Harwood 1994; shown for cyanobacteria and higher plants by Murata and Los 2007). However, studies on fatty acid composition in Polar macroalgae (e.g. Graeve et al. 2002) and especially, studies addressing how the respective composition of fatty acids may be changed under varying conditions are scarce.

Especially, species endemic to Antarctica, as the red macrophyte Palmaria decipiens, should exhibit effective modes of adaptation to their environment, resulting in very low upper survival temperatures and a strong degree of shade adaptation (Wiencke et al. 1994; Bischoff-Bäsmann and Wiencke 1996). Since, baseline physiological characteristics of $P$. decipiens have been studied previously, for instance regarding temperature requirements and growth patterns (Wiencke and tom Dieck 1989; Wiencke 1990), pigment content (Lüder et al. 2001, 2002) or fatty acid composition (Graeve et al. 2002), and as P. decipiens represents a dominant macroalgal species densely populating the intertidal and shallow subtidal along the Antarctic Peninsula (e.g. Quartino et al. 2005), this endemic algal species is thus considered an ideal candidate to study mechanisms of adaptation.

Moreover, field studies on radiation and temperature interactions on Antarctic macroalgae are important in order to predict more precisely the effects of environmental changes on this very susceptible ecosystem. Therefore, we conducted mesocosm experiments on King George Island (South Shetland Islands, Antarctica) exposing adult thalli of Palmaria decipiens from different shore levels to different temperatures under natural solar radiation. By measuring photosynthetic parameters such as maximum quantum yield (Fv/Fm) and recording photosynthesis versus irradiance-curves, as well as analysing changes in pigment composition, D1 protein content and fatty acid composition, we investigated physiological responses to the combination of two (stress-) factors to test the following hypothesis: (1) subtidal specimens will exhibit a higher susceptibility towards higher irradiances and/or elevated temperatures, resulting in a decrease in D1 protein content and (2) intertidal specimens will maintain photosynthetic integrity, due to a higher stress resistance. This will shed light on general mechanisms of adaptive traits of a dominant Antarctic endemic macroalga.

\section{Materials and methods}

Study site and experimental set-up

The experiment was conducted during January and February 2008 at the Dallmann Laboratory/Jubany Base, King George Island, Antarctica $\left(62^{\circ} 14^{\prime} \mathrm{S}, 58^{\circ} 40^{\prime} \mathrm{W}\right)$. A detailed description of the physical and biological environment of the study site located at Potter Cove is provided by Wiencke et al. (2008). Specimens of the endemic pseudoperennial rhodophyte (as described by Wiencke and Clayton 2002) Palmaria decipiens (Reinsch) RW Ricker (1987) were collected in the intertidal area of Peñon Uno during low-tide conditions in about $80 \mathrm{~cm}$ depths. Twenty specimens, approximately 40 to $50 \mathrm{~cm}$ in size, were brought back to the station covered by water and black foil to avoid drought and light stress during transportation. Twenty subtidal specimens equal in size as intertidal specimens were collected by scuba diving in front of the Fourcade glacier in 8 to $10 \mathrm{~m}$ water depths and transferred to the station. Algal material was cleaned and cut into square-shaped fragments of about $15 \times 25 \mathrm{~cm}$, taken from the mid-thallus part. These fragments were exposed to the following conditions: two mesocosms $(100 \times 200 \times 35-\mathrm{cm}$ plastic tanks $)$ were installed at the coastline in front of the station. A submersed seawater pump provided a constant flow of natural seawater to the tanks. In cases of extreme low tide or ice scoring, the pump was removed occasionally. One of these tanks was temperature controlled by a cryostat to provide temperatures between 5 and $10^{\circ} \mathrm{C}$, whereas the second one maintained ambient water temperatures between 2 and $5^{\circ} \mathrm{C}$. Temperature was monitored by underwater temperature loggers (Testo 177-T2, Lenzkirch, Germany), and salinity 
was checked with a handheld refractometer (Atago S-10E, Tokyo, Japan). Within these tanks, three water-permeable plastic cages were installed for each set of specimens from different shore levels serving as the experimental unit. Algal material was exposed to the ambient light conditions for 23 days with the subtidal specimens being covered with black net gauze, to prevent excessive high light stress and thus, to ensure survival. Light measurements were conducted in air with a LiCor 1400 Data Logger equipped with a flat-head cosine corrected PAR quantum sensor (LICOR 190 SA, Li-Cor, Lincoln, NE, USA) at least four times each day and always at noon. Each measurement consisted of ten single values, resulting in the mean of a measuring point. These measurements form the basis for the mean PAR value per day. In the course of the experimental exposure, mean maximum irradiance of PAR reached $1516 \mu \mathrm{mol}$ photons $\mathrm{m}^{-2} \mathrm{~s}^{-1}$ in air and a mean minimum of $315 \mu \mathrm{mol}$ photons $\mathrm{m}^{-2} \mathrm{~s}^{-1}$ was recorded. Maximum irradiance of PAR reached a value of $2068.3 \mu \mathrm{mol}$ photons $\mathrm{m}^{-2} \mathrm{~s}^{-1}$ in February 2008. Overall, radiation conditions were highly variable according to prevailing weather conditions, as indicated by radiation measurements displayed in Table 1 . Comparing the radiation conditions in the tanks to the respective in situ conditions, minimum PAR was consistent with the irradiance intertidal specimens experience during low tide, and maximum PAR represented a fourfold increase compared to irradiances at 2-m water depths during high tide. For subtidal specimens, minimum PAR was nine times higher than at $8 \mathrm{~m}$ depths. Naturally, transferring

Table 1 PAR (photosynthetically active radiation) radiation measurements in $\mu \mathrm{mol}$ photons $\mathrm{m}^{-2} \mathrm{~s}^{-1}$ taken in air throughout the duration of the mesocosm experiment, conducted with a LiCor 1400 data logger equipped with a flat-head cosine corrected sensor (Li-190SA, LiCor)

\begin{tabular}{lcc}
\hline Date & \multicolumn{2}{l}{$\mu$ mol photons $\mathrm{m}^{-2} \mathrm{~s}^{-1}$} \\
\cline { 2 - 3 } & PAR at noon & Mean daily PAR \\
\hline 26 Jan 2008 & 1333.9 & 958.5 \\
28 Jan 2008 & 270.7 & 315.6 \\
30 Jan 2008 & 143.3 & 508.4 \\
01 Feb 2008 & 706.8 & 798.3 \\
03 Feb 2008 & 637.5 & 356.8 \\
05 Feb 2008 & 266.1 & 244.3 \\
07 Feb 2008 & 988.7 & 1029.4 \\
09 Feb 2008 & 1492.4 & 1110.6 \\
11 Feb 2008 & 1456.5 & 887.9 \\
13 Feb 2008 & 437.3 & 520.2 \\
15 Feb 2008 & 461.8 & 404.2 \\
17 Feb 2008 & 1059.0 & 1186.2 \\
\hline
\end{tabular}

Values presented are measurements taken at 12:00 local time King George Island, South Shetland Islands, as well as mean daily radiation ( $n=10$ per measurement, min. of $n=4$ per day, see Material and methods for details) subtidal specimens to shallow water depths results in an additional shift in spectral radiation conditions in general, namely increasing UV-radiation intensities. However, the potential effect of changing UV-irradiance on algal physiology was not addressed by our study.

Samples for photosynthetic measurements were taken every second day before noon (10 am to $11: 30$ am local time), and photosynthetic measurements were conducted immediately. For sampling, pieces of approximately $50 \mathrm{~mm}$ in diameter were randomly cut from the exposed fragments and transferred in darkness to the laboratory. After measurements, samples were dried carefully, frozen in liquid nitrogen and stored at $-80^{\circ} \mathrm{C}$ for later biochemical analysis. Samples for fatty acid analysis were lyophilised (Lyovac GT2 using a AMSO/FINN-AQUA pump) for $48 \mathrm{~h}$ and then kept dry at room temperature.

\section{Photosynthetic measurements}

Photosynthetic measurements such as the determination of maximum quantum yield of photosystem II (Fv/Fm) and photosynthesis vs. irradiance-curves (PI-curves) were conducted using a pulse amplitude modulated chlorophyll fluorometer (PAM 2100, Walz, Effeltrich, Germany) following the protocol by Hanelt et al. (1997a, b) and Bischof et al. (1998a, b) with pre-darkened samples. PI-curves were conducted by using the internal LED as light source emitting irradiances of 21.6 to $630.3 \mu \mathrm{mol}$ photons $\mathrm{m}^{-2} \mathrm{~s}^{-1}$ PAR. According to Schreiber et al. (1994), relative electron transport rate (rETR) was calculated as the product of the respective effective quantum yield and photon fluence rate. Subsequently, rETRmax was determined by curve fitting after Jassby and Platt (1976). The maximum quantum yield (Fv/Fm) represents a sensitive indicator of photosynthetic efficiency of the alga, which might be affected by high light intensities or stress exposure in general. Relative ETRmax is indicative for photosynthetic capacity and may reflect stress effects on D1 protein and photosynthetic secondary reactions (see Schreiber et al. 1994 for details; Bischof et al. 1998a, b).

\section{Biochemical analysis}

The phycobiliprotein content was determined after Beer and Eshel (1985). Frozen sample material was ground in liquid nitrogen and transferred into $100 \mathrm{mM}$ phosphate buffer, and extraction of phycobiliprotein content was accomplished after 20 min. of centrifugation. The supernatant was measured spectrophotometrically, and the equations by Beer and Eshel (1985) were applied for calculation. Chlorophyll $a$ content was determined after Lüder et al. (2002) using the modified protocol of Inskeep and Bloom (1985). Frozen samples were transferred into 
five $\mathrm{ml}$ of $\mathrm{N}, \mathrm{N}$-dimethylformamid and kept at $4^{\circ} \mathrm{C}$ for 4 days in the dark. Chlorophyll $a$ concentration was calculated by measuring the supernatant spectrophotometrically (UV-2401 PC, Shimadzu) and by using the equation by Lüder et al. (2002).

Changes in the concentration of D1 protein of photosystem II were determined by SDS-PAGE and subsequent Western Blotting, according to Bischof et al. (2000), using a D1-specific primary antibody (AS 01016 Chicken Anti PsbA, Agrisera, Vännäs, Sweden) and ab6754 (Abcam, Cambridge, United Kingdom), for secondary immunodecoration, labelling and quantification.

For fatty acid analyses, a defined amount of lyophilized algal biomass was homogenized and extracted in dichloromethane: methanol $(2: 1, \mathrm{v} / \mathrm{v})$ following the method described by Folch et al. (1957). Prior to extraction, an internal standard was added (23:0 FAME, fatty acid methylesters), and the samples were crushed by ultrasonification. For gas liquid chromatographic analysis of the fatty acids, methyl esters were prepared from aliquots of the extracted algae by transesterification with $3 \%$ concentrated sulphuric acid in methanol for $4 \mathrm{~h}$ at $80^{\circ} \mathrm{C}$. After extraction with hexane, FAMEs were analysed with a gas-liquid chromatograph (HP 6890, Hewlett-Packard GmbH, Waldbronn, Germany) on a capillary column $(30 \mathrm{~m} \times 0.25 \mathrm{~mm}$ I.D.; film thickness: $0.25 \mu \mathrm{m}$; liquid phase: DB-FFAP, J\&W, Cologne, Germany) using temperature programming (Kattner and Fricke 1986). FAMEs were identified by comparison with known standard mixtures. If necessary, identification of FAMEs was confirmed by GC-MS measurements. The total lipid concentration (TL) refers to the sum of total fatty acids methyl esters.

\section{Data treatment}

Experiments were set-up as a split-plot design with three replicates for each treatment. Mean values and standard deviations, and for values given as ratios and percentages, standard errors were calculated per treatment. Photosynthetic data $(\mathrm{Fv} /$ Fm) and percentages were arcsine transformed, and a twoway ANOVA was performed for the two factors depth and temperature and their interactions. Statistically significant differences were tested separately with Tukey-Kramer HSD (honestly significant different) posthoc test with $P<0.1$ according to Sokal and Rohlf (1995). $P$-values are indicated where applicable. Statistical analyses were performed using the JMP 6.0 software (SAS, Cary, NC, USA).

\section{Results}

In the course of the experiment, maximum quantum yield of photosystem II $(\mathrm{Fv} / \mathrm{Fm})$ exhibited little variation over
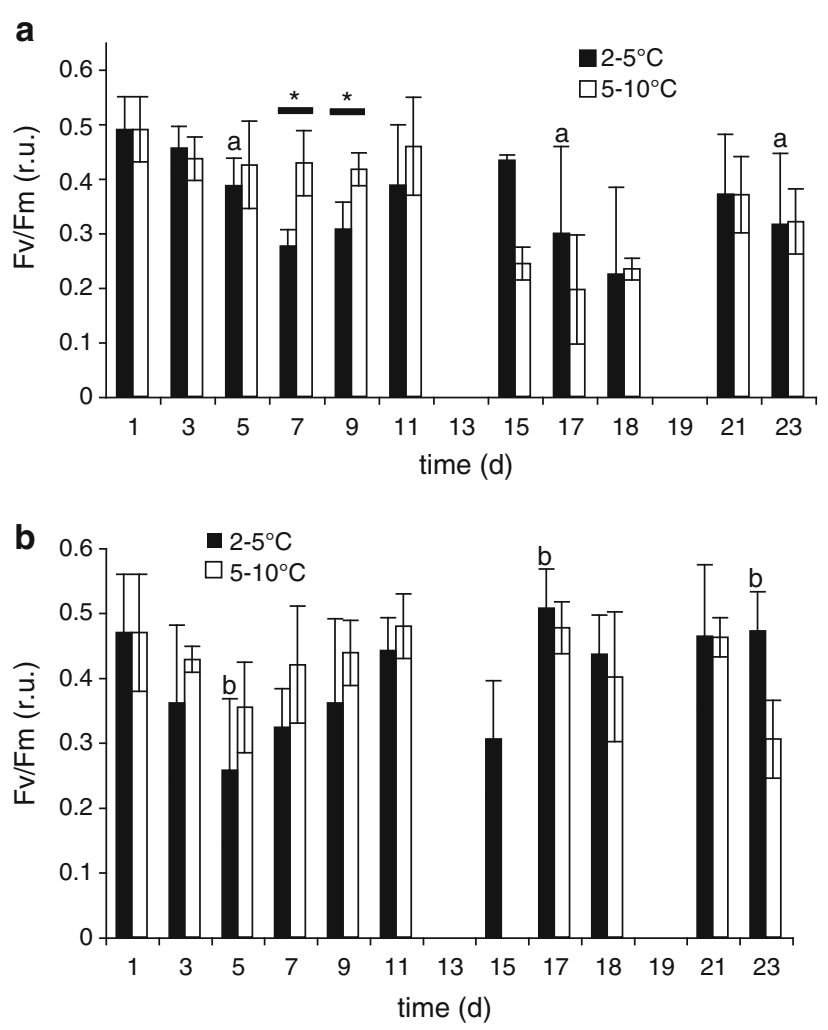

Fig. 1 a Maximum quantum yield $(\mathrm{Fv} / \mathrm{Fm})$ in the course of exposure time (in days) at two temperatures $\left(2-5^{\circ} \mathrm{C}\right.$, black bars and $5-10^{\circ} \mathrm{C}$, white bars) in specimens of intertidal Palmaria decipiens $\mathbf{b}$ subtidal specimens at the same temperature treatments as above. Values are means of triplicate measurements, bars show standard deviations. Asterisks represent significant differences between temperature treatments in specimens from the same shore level, different letters show significant differences in specimens from different shore levels within the same temperature treatment. r.u.: relative units

time and without a consistent pattern (Fig. 1). In the intertidal as well as in the subtidal specimens, initial Fv/Fm values of 0.47 relative units were recorded. Slightly higher values were observed in the $5-10^{\circ} \mathrm{C}$ temperature treatment during the first 13 days of exposure. During the ongoing exposure, only a mixed pattern was found, however, with on average higher values for subtidal specimens (approx. 0.4 relative units) than for intertidal specimens ( 0.3 relative units). This pattern was found for both temperature treatments (see Fig. 1a and b). Post-hoc analysis showed significant temperature effects only on day seven and nine for intertidal specimens. Significant differences between the two depths were recorded on days $5(P=0.0878), 17$ $(P=0.0136), 18(P=0.0417)$ and $23(P=0.0334)$.

A similar pattern was observed for rETRmax values (see Fig. 2a and b). Values for intertidal P. decipiens specimens decreased from an initial of 110 relative units to a final value of only 35 relative units without any significant difference between temperature treatments. rETRmax of 

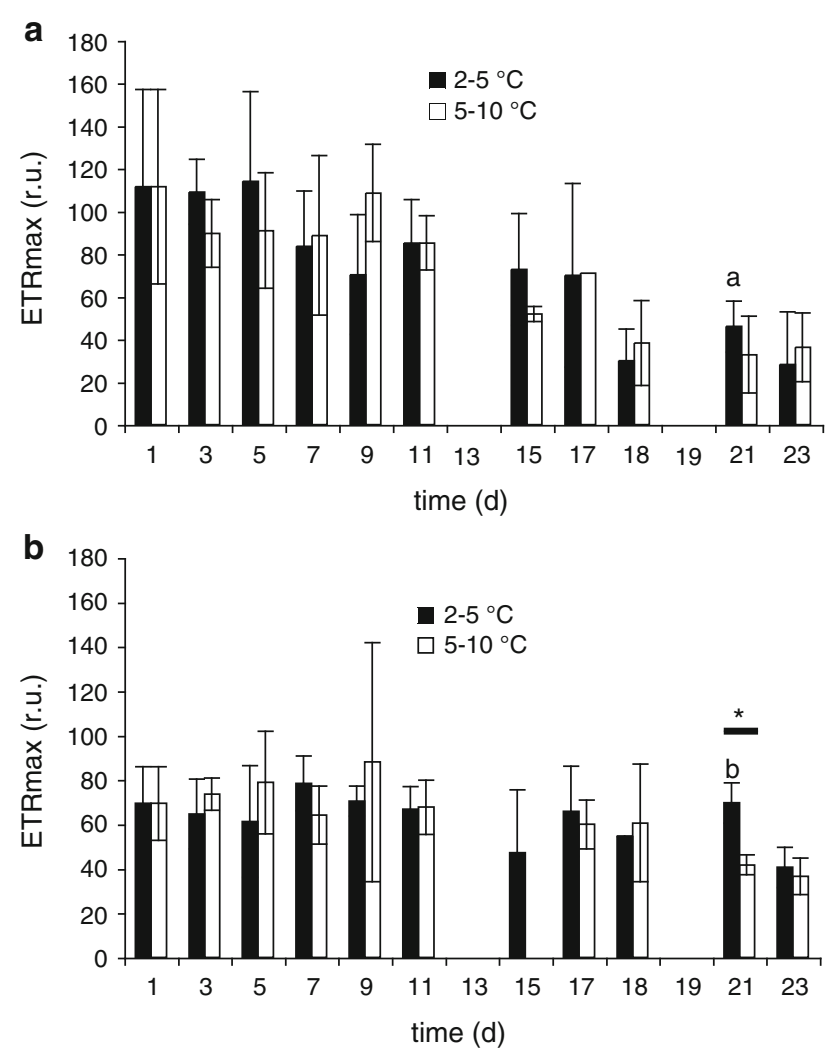

Fig. 2 a Relative maximum electron transport rate (rETRmax) in the course of exposure time (in days) at two temperatures $\left(2-5^{\circ} \mathrm{C}\right.$, black bars and $5-10^{\circ} \mathrm{C}$, white bars) in specimens of intertidal Palmaria decipiens b subtidal specimens at the same temperature treatments as above. Values are means of triplicate measurements, bars show standard deviations. Asterisks represent significant differences between temperature treatments in specimens from the same shore level, distinct letters represent significant differences in specimens from different shore levels in the $2-5^{\circ} \mathrm{C}$ temperature treatment. r.u.: relative units

subtidal specimens showed less variation during the exposure and decreased only slightly from an initial of 70 relative units to about 40 relative units (see Fig. 2b), exhibiting a significant temperature effect on day $21(P=0.0302)$.

The results of pigment analyses are presented as the ratio of phycobiliproteins to chlorophyll $a$ and revealed a decrease in pigment concentration for specimens of both depths (see Fig. 3). In intertidal specimens, the initial ratio decreased by $30 \%$ within the $2-5^{\circ} \mathrm{C}$ and by $75 \%$ at $5-10^{\circ} \mathrm{C}$, respectively. For subtidal specimens, an even more pronounced decline was observed: initial values decreased by $85 \%$ in the colder and by $79 \%$ in the warmer treatment. However, no significant differences were observed ( $P=0.1986$ and $P=0.6471$, respectively). Total concentrations of chlorophyll $a$ and phycobiliproteins decreased also, with a slightly more pronounced decline in subtidal specimens at $5-10^{\circ} \mathrm{C}$ (data not shown).

The results for D1 protein concentration are shown as the mean percentage of the initial value for both tempera-

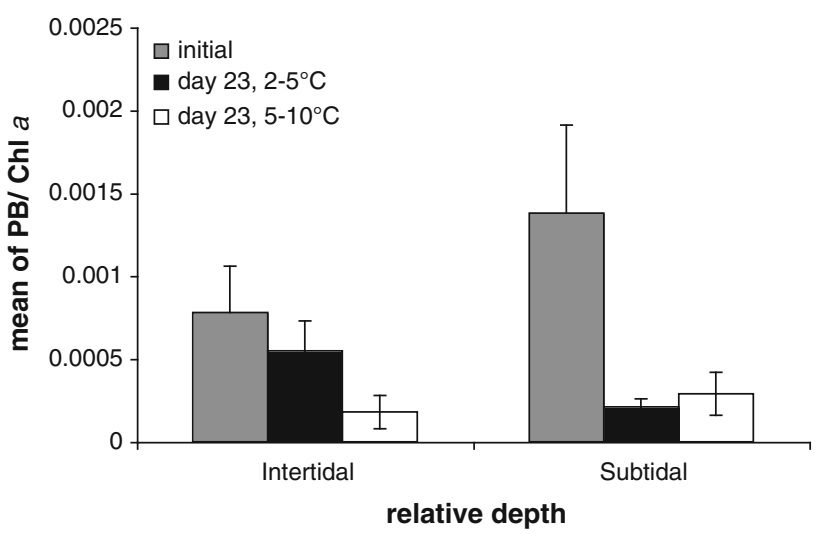

Fig. 3 Ratio of phycobiliproteins to chlorophyll a content in Palmaria decipiens from two different shore levels. Bars represent initial values ( rey) and final values after exposure for 23 days at two different temperatures $\left(2-5^{\circ} \mathrm{C}\right.$, black and $5-10^{\circ} \mathrm{C}$, white $)$. Values are means of triplicate measurements with standard error bars. No statistical significant differences were observed $(P>0.1)$

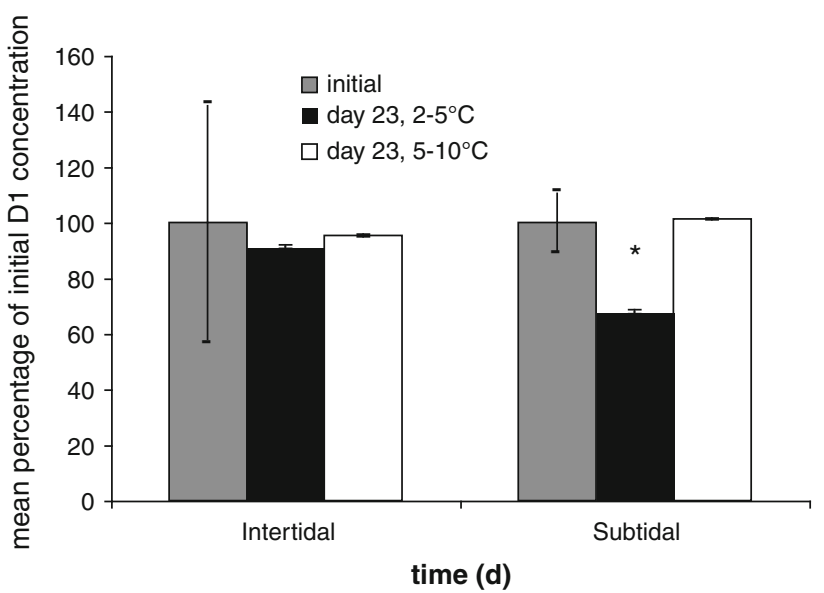

Fig. 4 Changes in D1 protein concentration of Palmaria decipiens from two different shore levels, given as the percentage of the initial value. Bars represent initial values (grey) and final values after exposure for 23 days at two different temperatures $\left(2-5^{\circ} \mathrm{C}\right.$, black and 5$10^{\circ} \mathrm{C}$, white). Values are means of triplicate measurements with standard error bars. Asterisk represents significant difference within the depth

ture treatments after 23 days of exposure (see Fig. 4). For intertidal specimens, no significant differences were found as values remained almost constant during exposure at both temperatures. In subtidal specimens, no differences between initial D1 concentration and values measured in specimens kept at $5-10^{\circ} \mathrm{C}$ were found $(P>0.1)$. In specimens exposed to lower temperatures, the protein concentration decreased significantly to about $68 \%$ of the initial value ( $P=0.0384$, one-way analysis with Tukey HSD posthoc test).

Changes in fatty acid (FA) composition are presented as mean ratio of saturated (i.e. no double bond) to unsaturated 

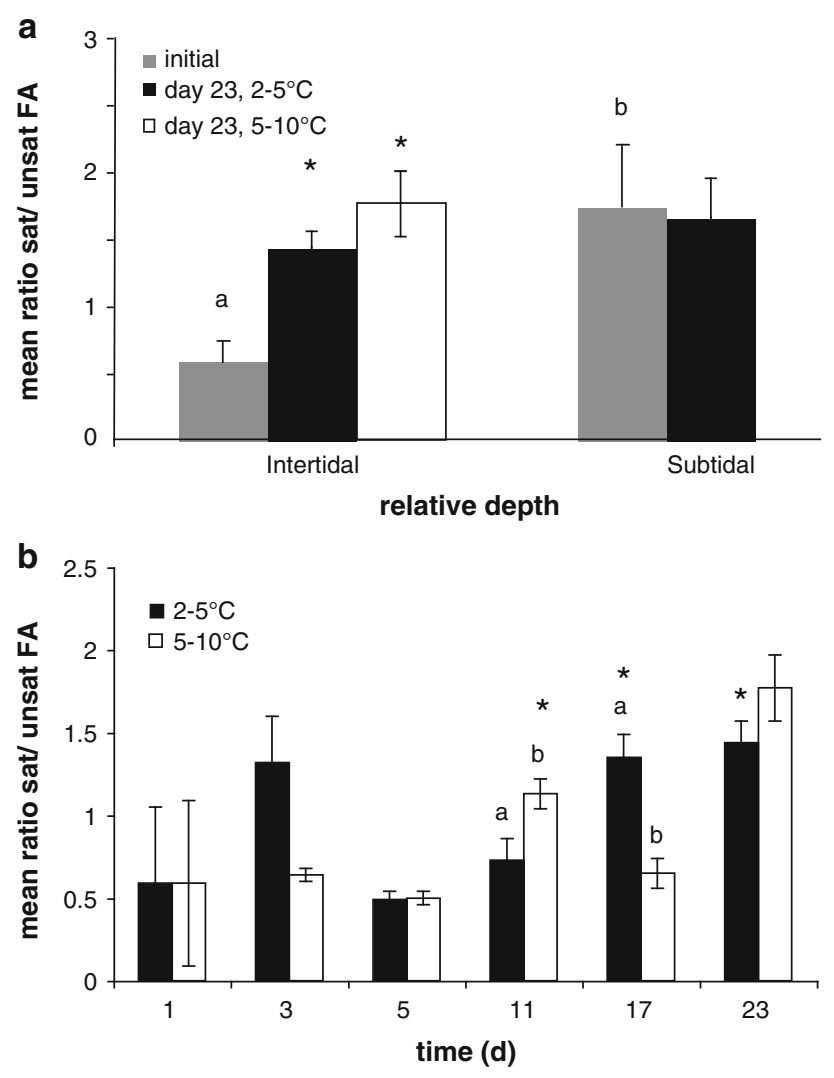

Fig. 5 a Fatty acid composition of Palmaria decipiens from two different shore levels, presented as the ratio of saturated to unsaturated fatty acids. Asterisks show significant differences in comparison to initial values within the respective depth, different letters indicate significant differences between initial values of both shore levels. Note that due to sample limitation, no values for subtidal specimens exposed to $5-10^{\circ} \mathrm{C}$ after 23 days are available b Fatty acid composition of intertidal $P$. decipiens versus exposure time in days. In both cases, bars represent initial values ( rey) and final values after exposure for 23 days at two different temperatures $\left(2-5^{\circ} \mathrm{C}\right.$, black and $5-10^{\circ} \mathrm{C}$, white $)$. Values are means of triplicate measurements with standard error bars. Bars marked with asterisks represent significant different FA composition within a temperature treatment to the respective initial ratio, different letters mark significant differences between temperature treatments on the respective sampling day

fatty acids (i.e. monounsaturated with 1 double bond and polyunsaturated with 2 or more double bonds) (see Fig. 5a). A detailed list of all fatty acids detected is shown in Table 2 for subtidal specimens and in Table 3 for intertidal specimens. Overall, 32 different FA were detected in this study, with 14:0, 15:0, 16:0, 18:0 and 20:0 as saturated FA. In total, the 16:0 fatty acid was the most abundant saturated FA and 20:5(n-3) the most abundant unsaturated FA. During the exposure of subtidal specimens, total lipid content remained at around $3.2 \mu \mathrm{g} \mathrm{mg}^{-1}$ dry weight (see Table 2). Within the initial samples of subtidal specimens of $P$. decipiens, the 16:0 FA was the most abundant saturated FA. During the exposure of 23 days, this pattern did not change at $5-10^{\circ} \mathrm{C}$. At $2-5^{\circ} \mathrm{C}$, the most abundant $\mathrm{FA}$ after the expo-
Table 2 Fatty acid content ( $\mu \mathrm{g} / \mathrm{mg}$ dry weight) of subtidal specimens of Palmaria decipiens exposed to two different temperatures $\left(2-5^{\circ} \mathrm{C}\right.$ and $5-10^{\circ} \mathrm{C}$ ) at ambient light conditions prevailing at Potter Cove between January and February 2008

\begin{tabular}{|c|c|c|}
\hline Fatty acid & Initial & Day $23\left(2-5^{\circ} \mathrm{C}\right)$ \\
\hline $14: 0$ & $0.420 \pm 0.05$ & $0.274 \pm 0.11$ \\
\hline $15: 0$ & $0.024 \pm 0$ & $0.009 \pm 0.01$ \\
\hline $16: 0$ & $1.170 \pm 0.02$ & $1.227 \pm 0.37$ \\
\hline $16: 1(n-7)$ & n.d. & $0.030 \pm 0$ \\
\hline $16: 2(n-4)$ & n.d. & n.d. \\
\hline $16: 3(n-4)$ & n.d. & n.d. \\
\hline $16: 4(\mathrm{n}-1)$ & n.d. & $0.006 \pm 0.01$ \\
\hline $18: 0$ & $0.466 \pm 0.18$ & $0.326 \pm 0.4$ \\
\hline $18: 1(n-9)$ & $0.279 \pm 0.02$ & $0.384 \pm 0.39$ \\
\hline $18: 1(n-7)$ & $0.057 \pm 0.02$ & $0.140 \pm 0.11$ \\
\hline $18: 2(n-6)$ & $0.064 \pm 0.01$ & $0.185 \pm 0.28$ \\
\hline $18: 3(n-6)$ & n.d. & n.d. \\
\hline $18: 3(n-3)$ & n.d. & $0.011 \pm 0.02$ \\
\hline $18: 4(n-3)$ & n.d. & n.d. \\
\hline $20: 0$ & $0.017 \pm 0.01$ & $0.024 \pm 0.04$ \\
\hline $20: 1(n-9)$ & $0.076 \pm 0$ & $0.041 \pm 0.02$ \\
\hline $20: 1(n-7)$ & n.d. & n.d. \\
\hline $20: 3(n-6)$ & n.d. & n.d. \\
\hline $20: 4(n-6)$ & $0.016 \pm 0$ & $0.010 \pm 0.02$ \\
\hline $20: 4(n-3)$ & n.d. & n.d. \\
\hline $20: 5(n-3)$ & $0.501 \pm 0.32$ & $0.485 \pm 0.41$ \\
\hline $22: 1(n-9)$ & $0.092 \pm 0.01$ & $0.051 \pm 0.01$ \\
\hline $22: 1(n-7)$ & n.d. & $0.058 \pm 0.09$ \\
\hline $22: 5(n-3)$ & n.d. & n.d. \\
\hline $22: 6(n-3)$ & n.d. & n.d. \\
\hline $\mathrm{TL}(\mu \mathrm{g} / \mathrm{mg})$ & $3.2 \pm 0.21$ & $3.33 \pm 1.46$ \\
\hline
\end{tabular}

Values of FA are given in $(\mu \mathrm{g})$ and are means of three replicates with standard deviation $( \pm \mathrm{SD})$. Total lipid $(\mathrm{TL})$ is given in $(\mu \mathrm{g} / \mathrm{mg}$ dry weight). n.d. $=$ not detected. Due to sample limitation, no FA data is available for specimens exposed to $5-10^{\circ} \mathrm{C}$

sure was 18:0. Highest amounts of unsaturated FA were detected for $20: 5(\mathrm{n}-3)$ with $0.501 \mu \mathrm{g} \mathrm{mg}^{-1}$ dry weight, followed by $18: 1(\mathrm{n}-9)$ with $0.466 \mu \mathrm{g} \mathrm{mg}^{-1}$ dry weight, 18:2(n-6) with $0.064 \mu \mathrm{g} \mathrm{mg}^{-1}$ dry weight and $18: 1(\mathrm{n}-7)$ with $0.057 \mu \mathrm{g} \mathrm{mg}^{-1}$ dry weight (see Table 2). Apart from 20:5(n-3), all FA increased in concentration during the exposure, but nevertheless did not reach values as high as 20:5(n-3).

In intertidal specimens, a decrease in total lipid content was found during the exposure in both temperature treatments: initial values of $7.9 \mu \mathrm{g} \mathrm{mg}^{-1}$ dry weight decreased to values of $3.3 \mu \mathrm{g} \mathrm{mg}^{-1}$ dry weight and $3.0 \mu \mathrm{g} \mathrm{mg}^{-1}$ dry weight, respectively (see Table 3 ). In intertidal specimens, a significantly increased amount of saturated fatty acids in comparison to the initial value was found in both 


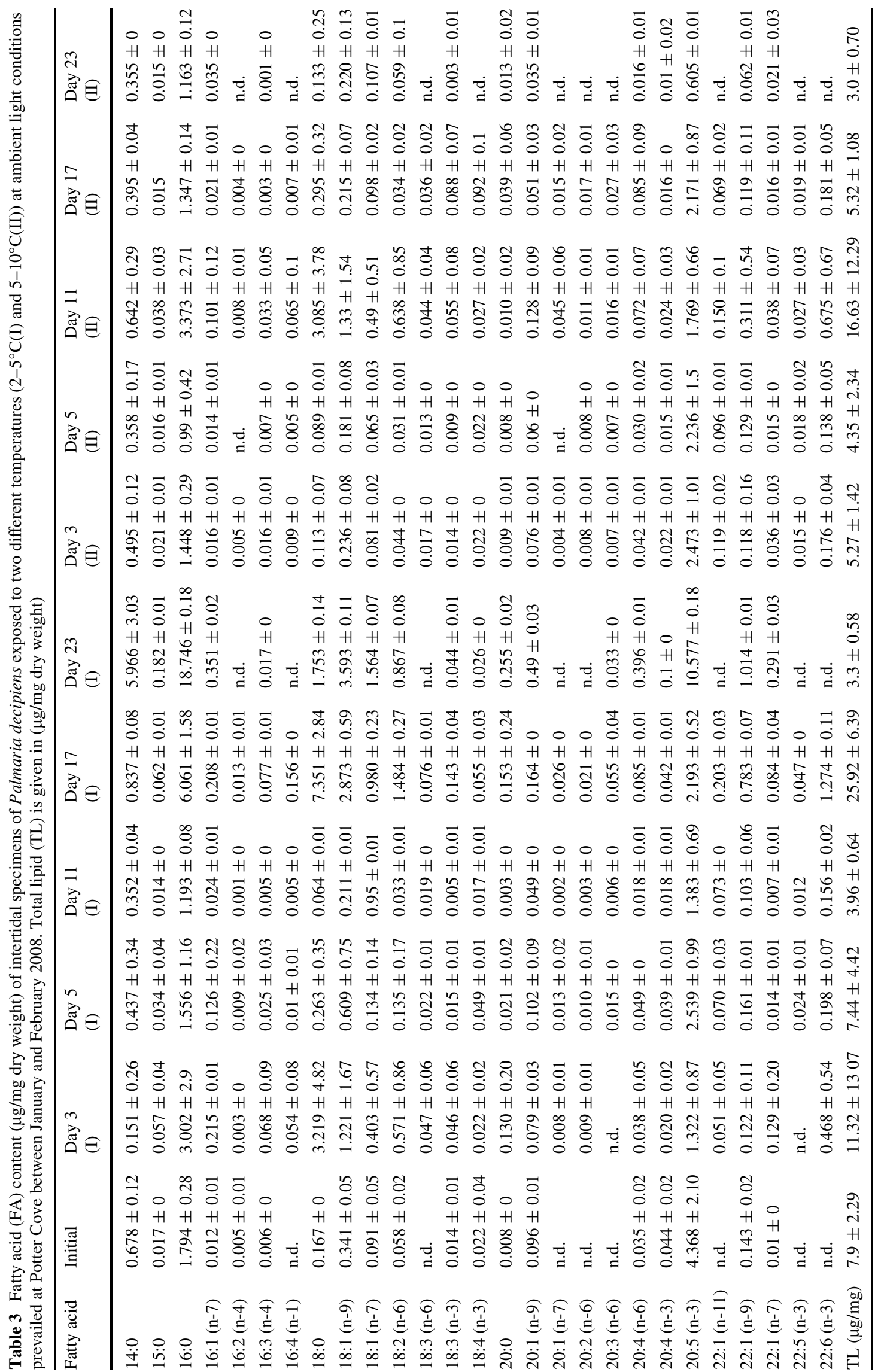


temperature treatments (Tukey HSD posthoc with $P<0.05$ ), especially regarding $16: 0$ fatty acid where initial values of $1.794 \mu \mathrm{g} \mathrm{mg}^{-1}$ dry weight increased to amounts of $18.764 \mu \mathrm{g} \mathrm{mg}^{-1}$ dry weight and 18:0 with initial values of $0.167 \mu \mathrm{g} \mathrm{mg}^{-1}$ dry weight which increased to values of $1.753 \mu \mathrm{g} \mathrm{mg}^{-1}$ dry weight (see Table 2). Values increased in the cold treatment from an initial ratio of 0.59 to 1.44 , and to even slightly higher ratios in the warm treatment to 1.77 by the end of the exposure. Initial ratios of saturated to unsaturated FA differed significantly between specimens of the two shore levels (Tukey HSD posthoc with $P<0.05$, see Fig. 5a). Intertidal specimens exhibited a higher amount of unsaturated FA. When regarding the ratios of saturated to unsaturated FA, specimens of both shore levels exhibited elevated amounts of PUFAs during the exposure (see Tables 2 and 3).

A second analysis on intertidal specimens was performed in order to test for the course of fatty acid composition over time. Therefore, samples additionally collected on day 3, 5, 11 and 17 were analysed, indicating an acceleration of fatty acid turnover after day 11 of exposure (see Fig. 5b). A significant temperature effect was detected on day $11(P=0.0241)$ and day $17(P=0.0192$, ANOVA with subsequent Tukey HSD posthoc test). Within the $2-5^{\circ} \mathrm{C}$ temperature treatment, FA composition differed significantly from the initial value on days $17(P=0.0107)$ and $23(P=0.0152)$, and in the warmer treatment on day $11(P=0.00243)$.

\section{Discussion}

In the study presented the endemic Antarctic macroalga $P$. decipiens exhibited a flexible photosynthetic response to experimental treatments confirming the high degree of physiological adaptation to the range of environmental variables at their growth site and indicating that changes in fatty acid composition may play an important role in the acclimation process. The experiment was designed to expose specimens to a more natural range of environmental parameters in the field (Wiencke et al. 2008), underlining the ecological relevance of findings in contrast to laboratory experiments, which tend to exceed the typical range of abiotic factors. Measurements of water temperatures up to $8^{\circ} \mathrm{C}$ in tide pools on King George Island (Abele et al. 1999) and even as high as $18^{\circ} \mathrm{C}$, as measured in the area of Gerlach Strait (in tide pools, Gustavo Ferreyra, personal communication) confirm that the experimental temperature range applied was well in the range of natural conditions. However, the mesocosm set-up was by far not designed to match the whole variety of changing abiotic and biotic parameters occurring in situ, as our study focussed on the interactive effects of just two environmental parameters on algal physiology.
Although only minor variances and few consistent differences in photosynthetic responses related to the experimental temperature treatments were observed, the importance of light/temperature interactions is still indicated by our data: On average, maximum quantum yield as well as rETRmax was exhibiting slightly higher values by the end of exposure to higher temperatures. This might be indicative for a compensation of photoinhibition by elevated temperatures, as previously demonstrated for Laminaria species and subantarctic green algae, respectively (Bruhn and Gerard 1996; Rautenberger and Bischof 2006). Due to a temperature-mediated elevated activity of photosynthetic secondary reactions, electrons might be drained off more efficiently from the electron transport chain, thus reducing the likelihood for photoinhibition. Due to the primary effect of temperature on enzymatic reactions, rETRmax, i.e. the photosynthetic capacity, seems to be slightly more affected as photosynthetic efficiency (see Figs. 1 and 2). However, this interaction is only effective within the general temperature tolerance range of the respective species. Thus, there is a strong light/temperature interaction within eurythermal macroalgal taxa, like Ulva (Rautenberger and Bischof 2006) or Laminaria (Bruhn and Gerard 1996), and only slight responses being observed for stenothermal species like $P$. decipiens (this study; Wiencke et al. 1994; BischoffBäsmann and Wiencke 1996).

Initial values for rETRmax do also display the differential degree of acclimation to the respective radiation conditions at the respective shore levels, as a general trend in algal ecophysiology along a depth gradient (Hanelt et al. 1997a; Wiencke and Clayton 2002). Despite their occurrence in the intertidal, Antarctic macroalgae are generally considered as being shade adapted (Kirst and Wiencke 1995); however, at the given radiation conditions at the Antarctic Peninsula, intertidal macroalgae can be exposed to irradiances as high as $2068 \mu \mathrm{mol}$ photons $\mathrm{m}^{-2} \mathrm{~s}^{-1}$ under low-tide conditions. Thus, Antarctic intertidal algae may be even stronger characterised by their flexible response towards changing radiation conditions, which may also include their ability for dynamic photoinhibition (Hanelt et al. 1994, 1997a). However, these former studies neglected the interactive influence of temperature.

On the level of photosynthetic pigments, no significant temperature effect was found. The considerable reduction in the total amount of pigments and also the ratio of phycobilliproteins to chlorophyll $a$ thus represent a response to altered radiation conditions. Palmaria decipiens is known to adjust its photosynthetic apparatus by changing pigment ratios and overall content to seasonal changes in radiation conditions (Lüder et al. 2001). In line with the pronounced differences in maximal photosynthetic rates related to the respective growth site of specimens, also the content and ratio of photosynthetic pigments differed largely between 
species from different shore levels. In subtidal $P$. decipiens, the ratio of pycobiliproteins to chlorophyll $a$ was much higher than in intertidal specimens. By increasing the amount of antennae pigments such a phycobiliproteins, light harvesting becomes more efficient at greater depths, whereas, vice versa, excessive light absorption is avoided by lower pigment concentrations in high light environments near the water surface. Furthermore, phycobiliproteins are known to degrade rapidly under exposure to high light and UV-radiation, while other pigment types are less susceptible (Tevini 1994; Gómez et al. 2004). However, the reduction in pigment concentration and composition observed in our study has to be considered as an acclimation mechanism rather than a result of photodamage as photosynthetic performance was hardly impaired (see Figs. 1, 2 and 3).

The maintained integrity of photosynthetic functions is also mirrored by only minor variations in D1 protein content. However, one particular treatment indeed resulted in a pronounced loss of D1: the exposure of subtidal specimens at low temperatures. It has to be considered that even under the protective shield of the black gauze, experimental irradiance exceeded in situ conditions nine times, which may result in an increased fragmentation of the protein (Aro et al. 1993; Osmond 1994). However, whether there is an interactive effect of temperature involved in this pronounced degradation is doubtful as the low temperature treatment is rather close to in situ temperature conditions. In contrast, in the higher temperature treatment, pronounced D1 fragmentation might have been counterbalanced by faster resynthesis of degraded protein or facilitated reintegration by an increased fluidity of thylakoid membranes.

Our results indicate that an important factor in acclimation to changing light and temperature conditions is fatty acid composition. Previously, no studies have addressed changes in fatty acid composition in short-term experiments as an acclimation mechanism in Antarctic macroalgae. Nevertheless, it has been shown by Leu et al. (2006) that light has an effect on algal fatty acid composition: the course of phytoplankton blooms from the peak to the early breakdown stage is characterised by a high light-induced decrease of polyunsaturated FA as well as an increase of monounsaturated fatty acids and a higher amount of the saturated FA 18:0 (Leu et al. 2006). This increase of 18:0 fatty acid in phytoplankton from Antarctic waters was also reported by Fahl and Kattner (1993) and was related to the poor quality of the particular organic matter. In combination with the findings of Leu et al. (2006), an increase of 18:0 FA may point to phytoplankton in a poor physiological condition at the end of a bloom. In our study, an increase of 18:0, 18:1 and 18:2 occurred in subtidal and intertidal specimens in both temperature treatments. This result taken together with decreasing rETRmax values as well as a significantly decreased amount of D1 protein may also point to a strain in physiological conditions of Palmaria decipiens.

An adjustment of fatty acids due to changing experimental temperatures was apparent in intertidal as well as in subtidal specimens exposed at $5-10^{\circ} \mathrm{C}$. In these cases, the amount of saturated fatty acids increased, which would result in more rigid membranes compared to the fluidity at $2-5^{\circ} \mathrm{C}$. This could be considered as an acclimatory response to elevated temperatures compared to in situ conditions. Thus, by changing the fatty acid composition in respect to changing temperatures, the membrane fluidity may be maintained. The respective degree of saturation/ desaturation of membranes is a crucial parameter to maintain optimum membrane fluidity (Harwood and Guschina 2009). Although initial total lipid content was equal in specimens from the two shore levels, the pronounced differences in fatty acid composition in initial values of subtidal and intertidal specimens may be explained by the different temperature ranges algae are exposed to at their specific growth site. The subtidal is a very stable environment with only minor variations in temperatures ranging between $-1.8^{\circ} \mathrm{C}$ and $+2^{\circ} \mathrm{C}$ (Wiencke and Clayton 2002; Wiencke et al. 2008). In contrast, in the intertidal temperatures may vary largely due to tidal changes and atmospheric forcings. During low tide, organisms may be either exposed to deep subzero temperatures, but also to elevated atmospheric temperatures up to $10^{\circ} \mathrm{C}$ (Arnaldo Dimuro, personal communication, meteorologist of Jubany Base in 2008) and may be submerged again shortly after by the water column with the incoming flood. In order to keep membranes fluid even under extreme temperature conditions in the intertidal, a high amount of unsaturated fatty acids has to be maintained (Phleger 1991; Nelson et al. 2002). Nelson et al. (2002) showed that in macroalgae from the northeastern Pacific, lipid content varies seasonally and that environmental temperature determines fatty acid composition. Our data supports this finding with respect to short-term temperature responses. De novo synthesis of fatty acids starts with acetyl CoA, which is elongated to $14: 0$ and 16:0 and then desaturated and further elongated by various elongases and desaturases in different steps (Harwood and Guschina 2009, and references therein). Thus, future studies should focus on how the latter reactions are triggered and modified by environmental conditions. According to Graeve et al. (2002), Polar macroalgae are rich in polyunsaturated fatty acids (PUFA), which are constituents of the phospholipids. Generally, biological activity is related to the essential PUFAs, and especially, phospholipids are considerably important for the functionality of photosynthetic membranes (Sanina et al. 2004; Aro et al. 2005). It is essential to all organisms to maintain membranes operative, especially those containing the photosynthetic machinery, in a wide 
range of changing environmental factors. In our study, no changes in fatty acid composition was found in subtidal $P$. decipiens exposed to temperatures that are similar or moderately increased compared to the in situ conditions. The ratio of saturated to unsaturated FA remained the same, although irradiance did strongly increase compared to the respective growth site. For a re-integration of de novo-synthesized D1 protein into the thylakoid membrane of PS II, degraded protein is transferred from the grana to the stroma site of the chloroplast by lateral diffusion (Aro et al. 2005), and newly synthesized protein needs to be transferred back to the grana site. This process is dependent on membrane fluidity. If in our results, D1 concentration decreases due to slowed down de novo synthesis or due to impaired re-integration of D1 into the membrane or just because D1 turnover is unbalanced under excessive light intensities, is still debatable. However, it is clearly shown that under the latter conditions D1 degradation was favoured and the efficient reintegration might have been precluded, as fatty acid composition was not adjusted. It is thus assumed that in the presented study, fatty acid composition is solely triggered by temperature signals.

Overall our results clearly demonstrate the high flexibility of an endemic Antarctic red alga to respond to changes in abiotic conditions and that fatty acid composition plays a key role even in short-term responses. Future studies should focus in more detail which mechanisms and signal transduction pathways govern the regulation of fatty acid composition. This would certainly strengthen our understanding of physiological acclimation mechanisms to Polar conditions.

Acknowledgments Funding by the Deutsche Forschungsgemeinschaft (DFG, Bi 772/7-1,2,3) is gratefully acknowledged. We are also thankful to Christian Wiencke as well as the AWI diving team for logistic support and sample supply. SB is grateful for Marie-Louise Kroon's help during the Antarctic campaign. The study has been performed upon agreement for cooperation between the Dirección Nacional del Antárctico (Argentina) and the Alfred Wegener Institute (Germany).

\section{References}

Abele D, Ferreyra GA, Schloss I (1999) $\mathrm{H}_{2} \mathrm{O}_{2}$ accumulation from photochemical production and atmospheric wet deposition in Antarctic coastal and off-shore waters of Potter Cove, King George Island, South Shetland Islands. Antarct Sci 11:131-139

Aro EM, Virgin I, Andersson B (1993) Photoinhibition of photosystem II. Inactivation, protein damage and turnover. Biochim Biophys Acta 1143:113-134

Aro EM, Suorsa M, Rokka A, Allahverdiyeva Y, Paakkarinen V, Saleem A, Battchikova N, Rintamaki E (2005) Dynamics of photosystem II: a proteomic approach to thylakoid protein complexes. J Exp Bot 56:347-356

Beer S, Eshel A (1985) Determing phycoerythrin and phycocyanin concentrations in aqueous crude extracts of red algae. Aust J Mar Freshw Res 36:785-792
Bischof K, Hanelt D, Wiencke C (1998a) UV-radiation can affect depth-zonation of Antarctic macroalgae. Mar Biol 131:597-605

Bischof K, Hanelt D, Tüg H, Karsten U, Brouwer PEM, Wiencke C (1998b) Acclimation of brown algal photosynthesis to ultraviolet radiation in Arctic coastal waters (Spitsbergen, Norway). Polar Biol 206:388-395

Bischof K, Hanelt D, Wiencke C (1999) Acclimation of maximal quantum yield of photosynthesis in the brown alga Alaria esculenta under high light and UV radiation. Plant Biol 1:435-444

Bischof K, Hanelt D, Wiencke C (2000) Effects of ultraviolet radiation on photosynthesis and related enzyme reactions of marine macroalgae. Planta 211:555-562

Bischoff-Bäsmann B, Wiencke C (1996) Temperature requirements for growth and survival of Antarctic rhodophyta. J Phycol 32:525-535

Bruhn J, Gerard VA (1996) Photoinhibition and recovery of the kelp Laminaria saccharina at optimal and superoptimal temperatures. Mar Biol 125:639-648

Fahl K, Kattner G (1993) Lipid content and fatty acid composition of algal communities in sea-ice and water from the Weddell Sea (Antarctica). Polar Biol 13:405-409

Folch J, Lees M, Stanley GHS (1957) A simple method for the purification of total lipids from animal tissues. J Biol Chem 226:497-509

Gómez I, López-Figueroa F, Ulloa N, Morales V, Lovengreen C, Huovinen P, Hess S (2004) Patterns of photosynthesis in 18 species of intertidal macroalgae from southern Chile. Mar Ecol Prog Ser 270:103-116

Graeve M, Kattner G, Wiencke C, Karsten U (2002) Fatty acid composition of Arctic and Antarctic macroalgae: indicator of phylogenetic and trophic relationships. Mar Ecol Prog Ser 231:67-74

Gurr MI, Harwood JL, Frayn KN (2002) Lipid Biochemistry. Blackwells, Oxford

Guschina IA, Harwood JL (2006) Lipids and lipid metabolism in eukaryotic algae. Progr Lipid Res 45:160-186

Hanelt D, Jaramillo MJ, Nultsch W, Senger S, Westermeier R (1994) Photoinhibition as a regulative mechanism of photosynthesis in marine algae of Antarctica. Ser Cient Inst Antart Chil 44:67-77

Hanelt D, Wiencke C, Nultsch W (1997a) Influence of UV radiation on the photosynthesis of Arctic macroalgae in the field. J Photochem Photobiol 38:40-47

Hanelt D, Melchersmann B, Wiencke C, Nultsch W (1997b) Effects of high light stress on photosynthesis of polar macroalgae in relation to depth distribution. Mar Ecol Prog Ser 149:255-266

Harwood JL (1994) Environmental factors effecting lipid metabolism. Prog Lipid Res 33:193-202

Harwood JL, Guschina IA (2009) The versatility of algae and their lipid metabolism. Biochi 91:679-684

Inskeep WP, Bloom PR (1985) Extinction coefficients of chlorophyll $a$ and $b$ in $N, N$-dimethylformamide and $80 \%$ acetone. Plant Physiol 77:483-485

Jassby AD, Platt R (1976) Mathematical formulation of the relationship between photosynthesis and light for phytoplankton. Limnol Oceanogr 21:540-541

Kattner G, Fricke HSG (1986) Simple gas-liquid chromatographic method for the simultaneous determination of fatty acids and alcohols in wax esters of marine organisms. J Chromatogr 361:263-268

Kirst GO, Wiencke C (1995) Ecophysiology of polar algae. J Phycol 31:181-199

Leu E, Falk-Petersen S, Kwasniewski S, Wulff A, Edvardsen K, Hessen DO (2006) Fatty acid dynamics during the spring bloom in a High Arctic fjord: importance of abiotic factors versus community changes. Can J Fish Aquat Sci 63:2760-2779

Lüder UH, Knoetzel J, Wiencke C (2001) Acclimation of photosynthesis and pigments to seasonally changing light conditions in the endemic Antarctic red macroalga Palmaria decipiens. Polar Biol 24:598-603 
Lüder UH, Wiencke C, Knoetzel J (2002) Acclimation of photosynthesis and pigments during and after six months of darkness in Palmaria decipiens (Rhodophyta): A study to simulate Antarctic winter sea ice cover. J Phycol 38:904-913

Murata U, Los DA (2007) Membrane fluidity and bemperature perception. Plant Phvsiol 115:875-879

Nelson MM, Phleger CF, Nichols PD (2002) Seasonal lipid composition in macroalgae of the northeastern Pacific ocean. Bot Mar 45:58-65

Osmond CB (1994) What is photoinhibition? Insights from comparisons of shade and sun plants. In: Baker NR, Bowyer JR (eds) Photoinhibition of photosynthesis from molecular mechanisms to the field. BIOS Scientific Publishers, Oxford, pp 1-24

Peterson ME, Daniel RM, Danson MJ, Eisenthal R (2007) The dependence of enzyme activity of temperature: determination and validation of parameters. Biochem J 402:331-337

Phleger CF (1991) Biochemical aspects of bouyancy in fishes. In: Hochachka PW, Mommsen TP (eds). Elsevier Science, Holland, pp 209-247

Quartino ML, Zaixso HE, Boraso de Zaixso AL (2005) Biological and environmental characterization of marine macroalgal assemblages in Potter Cove, South Shetland Islands, Antarctica. Bot Mar 48:187-197

Rautenberger R, Bischof K (2006) Impact of temperature on UV-susceptibility of two Ulva (Chlorophyta) species from Antarctic and Subantarctic regions. Polar Biol 29:988-996

Ricker RW (1987) Taxonomy and biogeography of macquarie Island seaweeds. British Museum (Natural History), London, pp 218-225
Sanina NM, Goncharova SN, Kostetsky EY (2004) Fatty acid composition of individual polar lipid classes from marine macrophytes. Phytochem 65:721-730

Schreiber U, Bilger W, Neubauer C (1994) Chlorophyll fluorescence as a non-intrusive indicator for rapid assessment of in vivo photosynthesis. In: Schulze E-D, Caldwell MM (eds) Ecophysiology of photosynthesis. Ecol Stud Anal Synth 100, pp 49-70

Sokal RR, Rohlf FJ (1995) Biometry - the principles and practice of statistics in biological research. Freeman, New York

Tevini M (1994) UV-B effects on terrestrial plants and aquatic organisms. Springer, Berlin, pp 175-190

Wiencke C (1990) Seasonality of red and green macroalgae from Antarctica-A long-term culture study under fluctuating Antarctic daylengths. Polar Biol 10:601-607

Wiencke C, Clayton MN (2002) Antarctic seaweeds. ARG Gantner Verlag KG, Ruggell, Lichtenstein, Synopses of the Antarctic benthos $9,239 \mathrm{pp}$

Wiencke C, tom Dieck I (1989) Temperature requirements for growth and survival of macroalgae from Antarctica and southern Chile. Mar Ecol Prog Ser 59:157-170

Wiencke C, Bartsch I, Bischoff B, Peters AF, Breeman AM (1994) Temperature requirements and biogeography of Antarctic, Arctic and amphiequatorial seaweeds. Bot Mar 37:247-259

Wiencke C, Ferreyra G, Abele D, Marenssi S (2008) The Antarctic ecosystem of Potter Cove, King George Island (Isla 25 de Mayo) Synopsis of research performed 1999-2006 at the Dallmann Laboratory and Jubany Station. Rep Polar Mar Res 571:406 